\title{
IDENTIFIKASI POTENSI BAHAYA DAN PEMANTAUAN CRITICAL POINT, (HACCP) PRODUK MAKANAN PENERBANGAN
}

\author{
[Identification of Hazards and Critical Point Monitoring Potentials, (HACCP) Flight Food Products] \\ Musthofa Lutfi*, Bambang Dwi Argo, Sri Hartini \\ Jurusan Keteknikan Pertanian - Fakultas Teknologi Pertanian - Universitas Brawijaya \\ Jl. Veteran, Malang 65145 \\ *Email: lutfi@ub.ac.id
}

Diterima 8 April 2019/ Disetujui 31 Mei 2019

\begin{abstract}
HACCP has been known as a system that uses a systematic and preventive approach that is shown to biological, chemical and physical hazards through anticipatory and preventive measures by no relying on inspection and testing on the final product. The application of HACCP is not only for the food industry but can be applied to the catering industry, catering services and food at hotels and restaurants. For this reason, modern food companies really need to determine quality standards for the consumers they serve. The purpose of this study was to analyze the application of HACCP on aviation food products (Aerofood ACS SUB) by identifying potential hazards and applying Critical Control Points (CCP). The methods are 1) observation of Critical Control Points (CCP) performed at receiving (CCP 1), chiller and freezer (Storage) (CCP 2), cooking (CCP 3), blast chilling (CCP 4), portioning (CCP 5). 2) Microbiological sampling consisting of random raw material samples at each arrival, hand swab samples randomly in the production and operational areas, swab equipment samples were also taken according to random, Dry good samples were taken randomly in storage, random ice cube samples, water tab samples are taken according to the sample. The company has HACCP planning as a guide for all processes that will take place within the company. All are based on the principles of HACCP for the whole process. The implementation of critical control points is in 5 places, namely receiving, storage, cooking, chilling and portioning blast. At each of these critical points, the standard critical temperature is different. Materials that do not meet the standards are rejected for further processing. In terms of microbiological hazards, it is checked by testing samples on foodstuffs, ready to eat food, dry good, air test, hand swab, production equipment, water and ice cube. The implementation of each sample test has been determined by PT. Aerofood ACS Surabaya based on standard procedures. If the results of checking is not the standards, repairs are handled or changes in the flow of handling procedures.
\end{abstract}

Keywords: HACCP, CCP, Critical Limits, management system

\section{ABSTRAK}

HACCP telah dikenal luas diseluruh dunia sebagai suatu sistem yang menggunakan pendekatan sistimatis dan preventif yang ditunjukan kepada bahaya biologis, kimia dan fisik melalui langkah-langkah antisipatif dan pencegahan dengan tidak lagi mengandalkan pada pemeriksaan dan pengujian pada produk akhir. Penerapan HACCP tidak hanya untuk industri pangan melainkan dapat diterapkan pada industri catering dan jasa boga serta makanan di hotel dan restauran. Untuk itu perusahaan pangan modern sangat perlu untuk menentukan standart mutu untuk konsumen yang dilayaninya. Tujuan penelitian ini adalah menganalisis penerapan HACCP pada produk makanan penerbangan (Aerofood ACS SUB) dengan identifikasi potensi bahaya dan penerapan Critical Control Point (CCP). Metode yang digunakan dalam penelitian ini adalah 1) Pengamatan Critical Control Point (CCP) yang dilakukan di receiving (CCP 1), chiller dan freezer (Storage) (CCP 2), cooking (CCP 3), blast chilling (CCP 4), portioning (CCP 5). 2) Pengambilan sampel Mikrobiologi yang terdiri dari sampel raw material secara random disetiap kedatangan, sampel hand swab secara random di area produksi dan operasional, sampel equipment swab juga diambil sesuai random, sampel Dry good diambil secara random di storage, sampel ice cube secara random, sampel Water tab diambil sesuai sampel. Perusahan telah membuat perencanaan HACCP sebagai panduan untuk semua proses yang akan berlangsung didalam perusahaan. Semua disusun berdasarkan prinsip-prinsip HACCP untuk keseluruhan proses. Penerapan critical control point terdapat di 5 tempat yaitu receiving, storage, cooking, blast chilling dan portioning. Disetiap titik kritis ini, suhu kritis standart adalah berbeda beda. Bahan yang tidak memenuhi standard ditolak untuk diproses selanjutnya. Dalam hal bahaya mikrobiologi dilakukan pengecekkan melalui uji sampel pada bahan makanan, makanan ready to eat, dry good, uji udara, hand swab, peralatan produksi, air dan ice cube. Pelaksanaan masing-masing pengujian sampel sudah ditetapkan oleh PT. Aerofood ACS Surabaya berdasarkan prosedur standar. Jika hasil pengecekkan tidak memenuhi standart maka dilakukan perbaikan penanganan atau pengubahan alur prosedur handling.

Kata kunci: $\mathrm{HACCP}, \mathrm{CCP}$, Batas Kritis, management system 
Versi Online:

http://www.profood.unram.ac.id/index.php/profood e-ISSN: 2443-3446

\section{PENDAHULUAN}

Makanan merupakan salah satu komponen substansi yang dibutuhkan bagi tubuh, sehingga mutu makanan yang akan dimasukan dalam tubuh harus diperhatikan dari segi keamanan dan mutunya. Penerapkan mutu dengan menggunakan teknik pendekatan kualitas (Quality Contro), yang ada saat ini sangat tidak dimungkinkan untuk menghasilkan makanan yang akan menimbulkan masalah seperti yang dikhawatirkan. Terlebih lagi bahwa untuk menghasilkan makanan dengan tingkat kepercayaan (degree of confidence) yang sangat tinggi maka diperlukan prosedur pengujian (testing procedures) yang menggunakan sampel dalam jumlah yang sangat besar (El-deen, et al., 2016) Hal ini akan berakibat bahwa sebagian besar makanan yang diproduksi harus digunakan untuk keperluan pengujian sehingga hanya akan menyisakan sebagian kecil bahan makanan yang ada (Araújo, et al., 2018).

Keamanan pangan difokuskan untuk memastikan bahwa makanan tidak akan membahayakan kesehatan ketika disiapkan atau dikonsumsi. Hal ini terkait dengan seperangkat aturan dan teknik yang diperlukan untuk memastikan keamanan pangan disemua tahap rantai makanan, dalam konteks ini, sangat penting bahwa pengetahuan tentang masalah yang terkait dengan keamanan pangan adalah langkah pertama dalam pengejarannya (Latorres, et al., 2016).

HACCP telah identik dan sering dikaitkan dengan keamanan pangan dan diterapkan pada seluruh rantai pangan (Lin, 2017) dan penerapanya sudah diterbitkan pada SNI Sistem analisa bahaya dan pengendalianya serta penerapan dimuat di SNI No. 01-4852-1998. HACCP telah dikenal luas diseluruh dunia sebagai suatu sistem yang menggunakan pendekatan sistimatis dan preventif yang ditunjukan kepada bahaya biologis, kimia dan fisik melalui langkahlangkah antisipatif dan pencegahan dengan tidak lagi mengandalkan pada pemeriksaan dan pengujian pada produk akhir.
Penerapan HACCP tidak hanya untuk industri pangan melainkan dapat diterapkan pada industri catering dan jasa boga serta makanan di hotel dan restauran. Untuk itu perusahaan pangan modern sangat perlu untuk menentukan standart mutu untuk konsumen yang dilayaninya. Aerofood ACS merupakan perusahaan yang bergerak dalam pelayanan jasa boga penerbangan (Ayman, 2019) dengan pengalamannya selama 40 tahun sebagai penyedia airline catering bertaraf internasional. Makanan yang dibuat dalam penerbangan akan berbeda sifatnya dengan layanan restoran. Karena makanan dalam penerbangan disajikan kepada pelanggan, waktu yang cukup lama setelah disiapkan dan dimasak dalam jumlah besar, kecerobohan dalam proses apa pun dapat berdampak penting pada rasa dan kesegaran makanan ( Lee dan Ko, 2016).

Seluruh cabang ACS saat ini mampu memproduksi sebanyak 55.000 porsi makanan setiap harinya. Dalam proses produksinya, ACS telah menerapkan standar internasional hal ini bisa dibuktikan oleh diraihnya sertifikat Quality Managemen System dengan standar ISO 9001: 2008 dan HACCP dengan standart ISO 22000 : 2005. Tujuan penelitian ini adalah menganalisis penerapan HACCP pada produk makanan penerbangan (Aerofood ACS SUB) dengan identifikasi potensi bahaya dan penerapan Critical Control Point (CCP).

\section{BAHAN DAN METODE}

\section{Alat dan Bahan}

Bahan dan perlalatan yang digunakan ini adalah seluruh komponen yang ada pada perusahaan terkait dengan proses semua kegiatan produksi makanan penerbangan di dalam perusahaan. Sedangkan bahan yang digunakan yaitu bahan baku dan pelengkap yang telah dikomposisikan menjadi makanan penerbangan Garuda Indonesia.

\section{Metode}

\section{a. Pengamatan Critical Control Point (CCP)}

Pengamatan dilakukan pada area-area yang menjadi ruang lingkup Critical Control 
Point (CCP) di Receiving (CCP 1), Chiller dan Freezer (Storage) (CCP 2), Cooking (CCP 3), Blast chilling (CCP 4), Portioning (CCP 5).

\section{b. Metode Pengambilan Sampel Mikrobiologi \\ Sampel makanan sesuai dengan} jadwal random dari setiap penerbangan, sampel raw material secara random di setiap kedatangan, sampel hand swab secara random, di area produksi dan operasional, sampel equipment swab juga diambil sesuai random, sampel dry good diambil secara random di storage, sampel ice cube juga diambil sampelnya sesuai random, sampel Water tab diambil sesuai sampel.

Sampel yang digunakan terdiri dari sampel makanan sesuai dengan jadwal random dari setiap penerbangan, sampel raw material secara random di setiap kedatangan, sampel hand swab secara random, di area produksi dan operasional, sampel equipment swab juga diambil sesuai random, sampel Dry good diambil secara random di storage, sampel ice cube juga diambil sampelnya sesuai random dan sampel Water tab diambil sesuai sampel.

Pengambilan data dan pengamatan dikukan secara langsung dengan cara menganalisis yang ada berhubungan dengan HACCP di seluruh area Aerofood ACS Surabaya. Wawancara dilakukan untuk memperoleh data yang dibutuhkan, dengan cara tanya jawab dengan pihak-pihak yang terkait seperti staf dan karyawan. Dokumentasi dilakukan untuk mencatat informasi yang didapat dari perusahaan dan dokumen-dokumen lain yang berhubungan dengan HACCP.

Data-data yang digunakan dalam penelitian ini adalah 1) data primer yang didapat pada saat melaksanakan pengamatan langsung. Hal yang didapat dengan data primer antara lain suhu, kualitas Bahan, komposisi bahan, produksi bahan dan pengecekan mikrobiologi, 2) data sekunder didapat dari data atau dokumen perusahaan. Data ini berupa
ISSN: 2443-1095

HACCP PLAN, standart bahan baku, Potensi bahaya dan Critical Control Point ( CCP) pada tiap tahapan.

\section{c. Pengolahan Data}

Pengolahan Data dilakukan dengan cara pendiskripsian keterangan hasil dari keseluruhan proses, potensi bahaya yang ditimbulkan, Titik kendali kritis dan pengujian keseluruhan sampel, kemudian diolah data tersebut dan disusun dengan cara menulis lembar kerja sehingga menjadi HACCP PLAN yang kemudian akan didokumentasikan sebagai record dari keseluruhan proses.

\section{HASIL DAN PEMBAHASAN}

\section{Pengamatan CCP (Titik kendali kritis) di PT. Aerofood ACS Surabaya 1.1 Pengamatan Receiving (CCP 1)}

Pada tahapan dimana suatu bahaya dapat dikendalikan haruslah mempunyai acuan yang jelas jika tidak didapat mencegah dan menghilangkan dapat berpotensi menimbulkan pertumbuhan mikroba patogen yang akhirnya akan berpengaruh pada makanan hasil akhir (ready to eat), dibawah ini merupakan Tabel 1 yang merupakan standar suhu yang menjadi pedoman selama pengiriman.

Tabel 1. Titik kritis suhu (CCP 1)

\begin{tabular}{|c|c|}
\hline $\begin{array}{c}\text { Critical } \\
\text { control point }\end{array}$ & Standar ACS \\
\hline $\begin{array}{c}\mathrm{CCP} 1 \\
\text { Receiving }\end{array}$ & $\begin{array}{l}\text { - } \text { Produk dingin } \\
\text { - Suhu produk } \leq 5^{\circ} \mathrm{C} \text {, apabila } \\
\text { suhu }>5^{\circ} \mathrm{C} \text { produk harus } \\
\text { segera dimasukkan ke } \\
\text { chiller. } \\
\text { - Apabila suhu }>8^{\circ} \mathrm{C} \text { produk } \\
\text { harus ditolak }\end{array}$ \\
\hline
\end{tabular}

Untuk standar yang dibuat, pada produk yang datang bersuhu dingin suhu produknya haruslah $\geq 5^{\circ} \mathrm{C}$. Produk harus segera mungkin dimasukkan dalam chiller karena mencegah timbulnya bahaya tumbuhnya bakteri patogen yang akan merusak raw material.

Semakin lama bahan material terpampang udara ruang maka semakin cepat pula bakteri patogen akan berkembang. Sesuai 
dengan (Tjahja dan Kadarsiman, 2008) yang menyatakan bahwa mutu bahan mentah harus didefinisikan dengan baik agar dapat dimengerti dengan jelas oleh pemasok bahan mentah, bagian pembelian, penerimaan barang maupun unit penyimpanan dan produk. Spesifikasi bahan mentah berguna untuk mengurangi (menghilangkan) penyimpanan. Sehingga material yang datang harus dicek terlebih dengan menggunakan spesifikasi yang telah ditentukan dan harus diukur keadaan suhunya untuk memastikan bahan tersebut aman untuk dikonsumsi. Jika semakin lama bahan terpampang oleh suhu ruang maka bahan tersebut akan cepat mengalami kerusakan (Balan, et al., 2018). Jadi harus segera mungkin disimpan dalam chiller. Keseluruhan bahan material yang digunakan di ACS terjaga kualitas dan mutunya.

\subsection{Pengamatan storage (CCP2)}

Pengamatan critical control point 2 yaitu dilakukan di store, yang merupakan tempat penyimpanan sementara bahan baku yang akan diproses. sedangkan penyimpanan untuk suhu ruang penyimpanan dingin $\leq 5^{\circ} \mathrm{C}$ dan suhu penyimpanana beku $-18^{\circ} \mathrm{C}$. Pada critical control point ke 2 yaitu storage, sangat penting untuk dikendalikan karena suhu penyimpanan yang tidak sesuai dapat menimbulkan pertumbuhan bakteri pada makanan, sehingga akan berpengaruh pada produk hasil akhir (ready to eat). Sedangkan suhu yang menjadi acuan standart critical control point 2 dapat dilihat pada Tabel 2 .

Tabel 2. Titik kritis suhu (CCP 2)

\begin{tabular}{cll}
\hline $\begin{array}{c}\text { Critical } \\
\text { control point }\end{array}$ & \multicolumn{2}{c}{ Standar ACS } \\
\hline CCP 2 & - Titik kritis untuk \\
(Storage) & penyimpanan dingin \\
& (chiller) dan menyimpan \\
& produk beku (frozen) \\
& - Suhu r ruang \\
& penyimpanana dingin $\leq$ \\
& $5^{\circ} \mathrm{C}$ sedangkan suhu \\
& penyimpanana beku - \\
& $18^{\circ} \mathrm{C}$ \\
\hline
\end{tabular}

Untuk critical control point di tempat penyimpanan suhu yang harus dikehendaki pada ruang dingin $\leq 5^{\circ} \mathrm{C}$, hal ini diupayakan harus mencapai suhu tersebut jika tidak mencapai suhu tersebut maka ruang penyimpanan akan segera diganti dengan menggunakan ruangan lain.

\subsection{Pengamatan Cooking (CCP 3)}

Suhu pemanasan pada saat pemasakan harus sesuai standart sehingga diperlukan cara penembakan termometer gun kearah makanan yang dimasak. Dibawah ini dapat dilihat pada Tabel 3 merupakan standart suhu untuk memasak yang telah diterapkan di Aerofod ACS Surabaya.

Tabel 3. Titik kritis suhu (CCP 3)

\begin{tabular}{cc}
\hline $\begin{array}{c}\text { Critical } \\
\text { control point }\end{array}$ & \multicolumn{1}{c}{ Standar ACS } \\
\hline CCP 3 & Titik kritis untuk pemasakan \\
(Cooking) & - Daging sapi, kambing, dan \\
& ayam dimasak dengan \\
& suhu minimal $74^{\circ} \mathrm{C}$ \\
& - Ikan dan shelfish dimasak \\
& dengan suhu minimal $65^{\circ} \mathrm{C}$ \\
& - Beef stak dimasak dengan \\
& suhu minimal $63^{\circ} \mathrm{C}$ \\
& - Telur dimasak dengan \\
& suhu minimal $63^{\circ} \mathrm{C}$ \\
& - Telur dimasak dengan \\
& suhu minimal $70^{\circ} \mathrm{C}$ \\
\hline
\end{tabular}

Titik kendali kritis sangat penting harus diperhatikan karena jika tidak perpengaruh akan berakibat fatal pada rantai proses, untuk itu daging sapi, kambing dan ayam haruslah dimasak dengan menggunakkan suhu minimal $74^{\circ} \mathrm{C}$, untuk ikan dimasak menggunakkan suhu minimal $65^{\circ} \mathrm{c}$. Telur dimasak dengan menggunakkan suhu $63^{\circ} \mathrm{C}$. Jika tidak dimasak dengan suhu yang telah distandartkan maka akan menyebabkan makanan mengandung bakteri, sehingga jika dikonsumsi akan menyebkan bahaya atau penyakit yang tidak dikehendaki.

\subsection{Pengamatan Blast chilling (CCP 4)}

Fungsi dari blast chilling lainnya yaitu menurunkan suhu makanan setelah memasak. Jika suhu pada saat proses blast chilling tidak sesuai juga akan berpotensi menimbulkan potensi bahaya biologi seperti tumbuhnya bakteri patogen seperti Bacilus cereus, Clostridium perfringens dll., sehingga akan mempengaruhi hasil akhir produk (ready to 
eat) untuk itu suhu dalam blast chill harus sesuai dengan standart yang ditentukan. Tabel 4 yang merupakan standart suhu critical control point yang harus dicapai oleh blast chiller.

Tabel 4.Titik kritis suhu (CCP 4)

\begin{tabular}{|c|c|}
\hline $\begin{array}{c}\text { Critical } \\
\text { control } \\
\text { point }\end{array}$ & Standar ACS \\
\hline $\begin{array}{l}\text { CCP } 4 \\
\text { ( Blast } \\
\text { chilling) }\end{array}$ & $\begin{array}{l}\text { - Titik kritis untuk } \\
\text { menurunkan suhu } \\
\text { makanan setelah dimasak } \\
\text { - Suhu makanan diturunkan } \\
\text { dari } 60^{\circ} \mathrm{C} \text { menjadi } 21^{\circ} \mathrm{C} \\
\text { dalam waktu } 2 \text { jam } \\
\text { - Apabila suhu makanan } \\
\text { tidak tercapai, makanan } \\
\text { dimasak kembali atau } \\
\text { dibuang }\end{array}$ \\
\hline
\end{tabular}

Blast chilling biasanya digunakan di jasa boga yang memiliki tingkat produksi yang tinggi, untuk itu setelah dilakukan pemasakan kemudian diturunkan suhunya di mesin blast chilling selama 2-3 jam dengan suhu $60^{\circ} \mathrm{C}$ menjadi $21^{\circ} \mathrm{C}$, jika sudah mencapai suhu yang diinginkan kemudian dipindahkan ke chiller jika ingin mengkonsumsi dilakukan pemanasan sesuai kebutuhan. Untuk keadaan masakan diblast chilling sendiri sebaiknya dilakukaan setiap 2 jam sekali harus dikeluarkan dan dipindahkan ke dalam chiller penyimpanan menurut (Mosteller et al., 2003) bahwa penyimpanan dingin di blast chilling harus juga memperhatikan suhu dan lamanya penyimpanan makanan, dikarenakan ada beberapa bakteri yang dapat tumbuh pada suhu dingin. Makanan yang berjenis bahan lain, hal ini akan memicu timbulnya basi pada makanan.

\subsection{Pengamatan Portioning (CCP 5)}

Bahaya pertumbuhan mikroba patogen, dikarenakan meningkatnya suhu ruangan selama portioning serta waktu pemaparan produk yang melebihi batas yang telah ditentukan sebaiknya dikendalikan dengan cara menghidari kontaminasi serta mengendalikan suhu dan waktu selama portioning. Dibawah ini merupakan Tabel 5, sebagai acuan standar suhu dan waktu di gunakan di ACS Surabaya selama portioning:

Tabel 5. Titik kritis suhu (CCP 5)

\begin{tabular}{cl}
\hline $\begin{array}{c}\text { Critical } \\
\text { control point }\end{array}$ & \multicolumn{2}{c}{ Standar ACS } \\
\hline CCP 5 & Merupakan titik kritis untuk \\
(Portioning) & setting makanan: \\
& - Suhu ruangan $<5^{\circ} \mathrm{C}$ \\
& - Suhu ruangan $>5^{\circ} \mathrm{C}$ sampai \\
& $<15^{\circ} \mathrm{C}$ waktu setting \\
& makanan tidak lebih dari 90 \\
& menit \\
& - Suhu ruangan $>15^{\circ} \mathrm{C}$ \\
& sampai $<21^{\circ} \mathrm{C}$, waktu \\
& setting makanan tidak lebih \\
& dari $45 \quad$ menit (suhu \\
& makanan maksimal $15^{\circ} \mathrm{C}$. \\
& - Suhu ruangan $>21^{\circ} \mathrm{C}$, waktu \\
& setting makanan lebih dari \\
& 45 menit (suhu makanan \\
& maksimal $\left.15^{\circ} \mathrm{C}\right)$ \\
& Apabila waktu seting tidak \\
& memenuhi, cek suhu \\
& makanan. Apabila waktu \\
& setting tidak memenuhi, cek \\
& suhu makanan. Apabila \\
& suhu makannan lebih dari \\
& $15^{\circ} \mathrm{C}$ makanan segera \\
& dibuang. $\quad$ \\
\hline
\end{tabular}

\section{Untuk}

proses

pemorsian

menggunakan suhu yang telah distandartkan untuk pemorsian suhu ruangan $>5^{\circ} \mathrm{C}$ sampai $<15^{\circ} \mathrm{C}$, waktu setting makanan tidak boleh lebih dari 90 menit, karena jika makanan di atas $15^{\circ} \mathrm{C}$ dan lama terpampang suhu ruang maka akan memicu percepatan pertumbuhan bakteri. Jika suhu ruangan $>150^{\circ} \mathrm{C}$ sampai $<210^{\circ} \mathrm{C}$, maka waktu yang diperlukan tidak boleh lebih dari 45 menit, kemudian untuk suhu $>21^{\circ} \mathrm{C}$, wakttu setting makanan lebih dari 45 menit dengan suhu makanan $15^{\circ} \mathrm{C}$. Jika semua makanan dicek maka suhu tidak mencapai standart maka makanan wajib dibuang dan tidak boleh dikonsumsi lagi. Hal ini sesuai dengan pendapat (Thaheer, 2005) bahwa kurangnya perlindungan dan keamanan dalam produksi pangan tidak saja akan menimbulkan gangguan pada kesehatan manusia, namun dapat pula menimbulkan kerugian ekonomi yang dapat diderita oleh konsumen. Sehingga proses porsioning harus mempunyai standart yang akan dijadikan 
acuan dalam proses pengerjaan oleh karyawan, sedangkan untuk menjaga makanan yang sudah melalui beberapa tahap pengerjaan secara benar sehingga proses portioning harus di amati titik kritisnya, seperti waktu dan suhu portioning (Araújo, W. et al., 2018).

\section{Hasil pengambilan sampel mikrobiologi}

Pemeriksaan mikrobiologi keseluruhan telah sesuai dengan Tabel 6. yang merupakan standart yang telah ditetapkan oleh AEA (Assosiation Eropa Airline) mengenai batasan mikrobiologi yang digunakan untuk makanan pesawat.

Tabel 6. Standar batasan mikrobilogi

\begin{tabular}{lcc}
\hline \multicolumn{1}{c}{ Mikrobiologi } & $\begin{array}{c}\text { Makanan } \\
\text { Panas }\end{array}$ & $\begin{array}{c}\text { Makanan } \\
\text { Dingin }\end{array}$ \\
\hline Total count & $1.0 \times 10^{5}$ & $\mathrm{NA}$ \\
& $\mathrm{CFU} / \mathrm{g}$ & \\
Enterobacteriaceace & $1.0 \times 10^{2}$ & $\mathrm{NA}$ \\
& $\mathrm{CFU} / \mathrm{g}$ & \\
Escherichia coli & $10 \mathrm{CFU} / \mathrm{g}$ & $\begin{array}{c}\text { Terdeteksi / } \\
\end{array}$ \\
Staphylococcus aureus & $1.0 \times 10^{2}$ & $1.0 \times 10^{2}$ \\
& $\mathrm{CFU} / \mathrm{g}$ & $\mathrm{CFU} / \mathrm{g}$ \\
Bacillus cereus & $1.0 \times 10^{2}$ & $1.0 \times 10^{3}$ \\
& $\mathrm{CFU} / \mathrm{g}$ & $\mathrm{CFU} / \mathrm{g}$ \\
Clostridium perfringens & $1.0 \times 10^{2}$ & $1.0 \times 10^{2}$ \\
& $\mathrm{CFU} / \mathrm{g}$ & $\mathrm{CFU} / \mathrm{g}$ \\
Salmonella spp & Terdeteksi & Terdeteksi / \\
& $/ 25 \mathrm{~g}$ & $25 \mathrm{~g}$ \\
\hline
\end{tabular}

Sumber: (AEA, 2006)

Dari hasil seluruh pemeriksaan uji mikrobiologi, semua yang diujikan seperti ready to eat, raw material, water tab, ice tube, equipment swab, hand swab, udara dan dry good ternyata mempunyai grade yang dijinkan dan baik sehingga menunjukkan hasil yang memuaskan dan diterima. Hal ini akan menghasilkan keamanan pangan Karena semua sesuai dengan standar mikrobiologi yang telah ditetapkan oleh ACS Surabaya, dan setara kesesuaiannya dengan standart mikrobiolgi yang telah dibuat oleh AEA (Assosiation Eropa Airline).

\section{Dokumen HACCP (HACCP)}

\subsection{Dokumen 1 : Tim HACCP (Hazard Analysis Critical Control Point)}

Tim HACCP (Hazard Analisis Critical

Control Point) di ACS dibentuk untuk membangun sistem keamanan pangan ISO 22000:2005 (HACCP) mulai dari perencanaan hingga penerapannya. Untuk menjamin itu semua harus ada keputusan yang dibuat dari tim dengan menejemen yang dibentuk dari personal departemen yang berada pada di jalur mutu. Khususnya yang berkaitan langsung dengan produksi. keanggotaan tim HACCP atau keamanan pangan di aerofood ACS surabaya dapat dilihat pada Tabel 7.

Tabel 7. Tim HACCP ACS Surabaya

\begin{tabular}{cc}
\hline Jabatan & Posisi \\
\hline General manager SUB & Ketua umum \\
QA manager & Anggota 1 \\
Production manager & Anggota 2 \\
Operation manager & Anggota 3 \\
Chief engineer & Anggota 4 \\
Human rescrs & Anggota 5 \\
manager & Anggota 6 \\
House keeping & \\
manager & \\
\hline
\end{tabular}

Untuk penyusunan anggota HACCP di perusahaan jasa boga ini, beranggotakan 7 anggota yang terdiri dari beberapa pimpinan atau perwakilan dari setiap departemen, kenapa demikian supaya memberikan contoh dan koordinasi kepada para staff di departemen yang dipimpinya. Untuk tugas tim sendiri yaitu memastikan bahwa sistem manajemen mutu yang berada di dalam perusahaan berjalan (Untuk anggota Tim HACCP di ACS terdiri dari General manager sebagai ketua umum yang menaungi perusahaan, kemudian anggota 1 manager dari departemen quality control, anggota 2 yaitu manajer produksi, anggota 3 manager operation, anggota ke 4 yaitu chief engineer, anggota 5 yaitu human research manager dan anggota ke 6 terakhir yaitu House keeping manager. Mereka yang nantinya akan mengondisikan agar rantai penjaminan mutu akan berjalan sesuai dengan instruksi yang telah ditetapkan. Semua sudah standar sesuai dengan ketetapan yang diijinkan. Hal ini sesuai dengan pendapat (European Commitee for Standarisation, 2004) bahwa Tim HACCP bisa terdiri dari 4 sampai dengan 10 orang yang mengusai produk proses dan potensi bahaya yang hendak diperhatikan. 


\subsection{Dokumen 2: Diskripsi produk akhir}

Produk merupakan hasil akhir yang dikehendaki setelah melewati beberapa proses yang berurutan secara baik dan benar. Produk yang diproduksi di Aerofood ACS ada beberapa macam, untuk itu dilakukan pendiskripsikan pada setiap produk yang dihasilkan, dalam pendiskripsian produk akhir ditulis dengan menggunakan tabel jenis proses dan jenis produk yang dihasilkan. Untuk jenis proses dilakukan penulisan informasi nama produk, komposisi, karakteristik produk, penggunaan produk, kemasan, metode pengawetan, konsumen, instruksi khusus pada label, usia simpan dan metode distribusi.

\subsection{Dokumen 3: Tujuan Penggunaan dan Konsumen Produk Makanan}

Pada tahap ini harus digambarkan konsumen yang akan mengunakan makanan dan diidentifikasi untuk siapa produk tersebut ditujukan, apakah untuk semua kalangan atau untuk kalangan tertentu saja. Untuk memudahkan pencatatan dan tujuan praktis, informasi mengenai tujuan penggunaan produk dan konsumen yang dituju biasanya disatukan dalam lembar isian deskripsi produk seperti pada informasi diatas. Bisa juga disajikan dalam lembar isian yang terpisah. Informasi mengenai target konsumen biasanya merupakan bagian dari deskripsi produk dan ditulis dalam satu tabel. Untuk konsumen dari produk yang diproduksi semua dikondisikan untuk penumpang umum dan penumpang pesawat (Meta et al., 2018). Untuk penumpang yang mempunyai kebutuhan khusus dapat memesan dengan katagori, anak-anak, vegetarian, dan muslim (Farah, et al., 2018). Hal ini difungsikan agar tidak terjadi resiko tinggi pada suatu produk jika dikonsumsi pada orang-orang yang mempunyai kebutuhan khusus.

\subsection{Dokumen 4: Diagram Alir Proses}

Diagram alir merupakan penggambaran alur yang dilalui untuk menghasilkan produk yang akan menerapkan HACCP harus disusun bagan alirnya. Untuk pembuatan bagan alir atau diagram alir yang dibuat harus memuat semua tahapan di dalam operasional produksi.
Deskripsi diagram alir sebaiknya dapat menggambarkan kondisi nyata proses produksi (Ko, Y., 2016).

Tujuan penyusunan bagan alir adalah untuk memberikan uraian tahapan-tahapan dalam proses secara jelas dan sederhana. Ruang lingkup bagan alir harus mencakup semua tahapan dalam proses yang secara langsung berada dibawah kendali pabrik pengolahan makanan (Moreb et al., 2017). Bagan alir juga dapat memasukkan tahapantahapan dalam rantai makanan sebelumnya dan sesudah pengolahan makanan yang terjadi dalam pabrik pengolahan.

\subsection{Dokumen 5: Verifikasi bagan alir di lapangan \\ Diagram alir yang telah disusun harus} diverifikasi dengan kenyataan dilapangan. Biasanya ada kemungkinan terjadi kesalahan ketika dilakukan penyusunan yang pertama. Jika terdapat kesalahan maka diagram alir harus segera diperbaiki. Verifikasi bagan alir di lapangan dilakukan dengan cara mengamati aliran proses, mencocokkan antara diagram alir dengan tahapan nyata dilapangan. Jika dinilai perlu, dapat dilakukan pengambilan sampel. Untuk verifikasi bagan alir dilapangan dilakukan oleh tim HACCP yang nantinya akan dikoordinasikan dengan staff di masing-masing departemen untuk melakukan verifikasi bagan alir di lapangan dengan pengamatan semua proses, karyawan, dan operasional rutin, jika tidak sesuai tim HACCP wajib mengubah alur proses. Sesuai dengan (BSN, 1998) Tim HACCP sebagai penyusun bagan alir harus mengkonfirmasikan operasional produksi dengan semua tahapan dan jam operasi serta bilamana perlu mengadakan perubahan bagan alir. Semua anggota tim HACCP harus terlibat dalam kegiatan verifikasi bagan alir.

\subsection{Dokumen 6: Identifikasi Bahaya (prinsip 1)}

Tim HACCP harus membuat daftar bahaya yang mungkin terdapat pada tiap tahapan dari produk utama pengolahan, manufaktur dan distribusi hingga sampai pada titik konsumen saat mengkonsumsi.

Tim HACCP mengadakan analisis bahaya untuk mengidentifikasi program HACCP 
dimana bahaya yang terdapat secara alami, karena sifatnya mutlak harus ditiadakan atau dikurangi hingga batas-batas yang dapat diterima, sehingga produksi pangan tersebut dinyatakan aman. Penyajian informasi untuk proses disajikan sama seperti penyajian pada proses produksi mulai dengan pengolahan air es, proses pembuatan makanan, proses pembuatan coklat dan pastry, proses frozen food. Untuk kolom analisa bahaya yang dimukinkan terdiri dari nomer, tahapan pada setiap proses, identifikasi bahaya terdiri dari beberapa tipe( fisik, kimia, biologi) dan bahaya, penyebab, penetapan bahaya, tindakan pengendalian, pohon keputusan, CCP/OPRP/PRP, alasan keputusan.

\subsection{Dokumen 7: Penentuan titik-titik} kendali kritis (CCP)

Metode penentuan CCP yang digunakana

di ACS Surabaya dilakukan melalui cara sebagai berikut:

a. Melakukan hazard analysis baik terhadap bahan baku maupun proses.Pada tahap ini ditentukan apakah proses atau bahan baku mengandung bahaya atau tidak. Hazard analysis meliputi bahaya biologi,kimia dan fisik.

b. Menetukan signifikasi bahaya melalui perkalian silang antara probability (tingkat kemungkinan bahaya terjadi) dan saverity (tingkat keparahan bahaya). Nilai signifikan perkalian kedua parameter tersebut disajikan pada Tabel 8.

Tabel 8. Nilai signifikasi

\section{Severity Low Medium High}

\begin{tabular}{lccc}
\hline High & $\mathrm{S}$ & $\mathrm{S}$ & $\mathrm{S}$ \\
Probability & $\mathrm{S}$ & $\mathrm{S}$ & $\mathrm{S}$ \\
Medium & $\mathrm{NS}$ & $\mathrm{S}$ & $\mathrm{S}$ \\
\hline
\end{tabular}

c. Berdasarkan signifikasi pada Tabel 8 , hasil perkalian antara severity dengan probability yang menghasilkan keputusan bahaya $\mathrm{S}$ (signifikan) diuji dengan menggunakan pohon keputusan CCP untuk menentukan apakah proses pada diagram alir tersebut merupakan CCP atau bukan. Sedangkan hasil perkalian kedua arameter tersebut yang menghasilkan keputusan bahaya NS (not significant) tidak perlu dilanjutkan pada pohon keputusan CCP. Diagram keputusan penentuan CCP disajikan dalam diagram pohon keputusan.

d. Berdasarkan pohon keputusan tersebut keputusan menetapkan

- CCP merupakan jawaban "yes" atas pertanyaan no 2 dan "no" atas jawaban pertanyaan no 4

- OPRP /CP merupakan jawaban "no" pada pertanyan no 3 dan jawaban "yes" atas pertanyaan no 4

- PRP jika suatu aktifitas merupakan persyaran dasr agar sistem keamanan pangan dapat berjalan dengan baik seperti kegiatan cleaning, pest control dll.

\subsection{Dokumen 8: Penentuan batas kritis}

Batas kritis adalah suatu kondisi atau keadaan yang menunjukkan perbedaan antara produk yang aman dan tidak aman. Batas kritis juga merupakan satu atau lebih tolenransi yang harus dipenuhi untuk menjamin bahwa suatu CCP secara efektif dapat mengendalikan bahaya mikrobiologis kimia dan fisik, Penentuan batas kritis dilakukan untuk setiap dan seluruh CCP yang bersifat dapat dijustifikasi, dapat diukur dan harus divalidasi.

\subsection{Dokumen 9: Penetapan prosedur pemantauan}

Rencana monitoring diupayakan dapat menjamin bahwa batas kritis tidak dilampaui . Monitoring di Aerofood ACS dilakukan dengan cara pematan visual atau dengan pengukuran dan pengujian terhadap batas kimia, fisik dan biologi. Untuk waktu monitoring direncanakan dan dijadwalkan secara preodik oleh semua kepala departemen. Jika tidak dimungkinkan untuk melakukan untuk melakukan pemantauan secara kontinyu maka perlu untuk menetapkan frekuensi pemantauan dan prosedur yang cukup dapat diandalkan untuk menunjukan bahwa CCP berada dibawah kendali. 


\subsection{Dokumen 10: Penetapan tindakan koreksi}

Jika ada penyimpangan pada batas kritis, tindakan koreksi dilakukan untuk memperbaiki serta merubah dari keseluruhan proses.

Sesuai dengan tujuan perusahaan untuk selalu memberi kepuasan kepada pelanggan, Aerofood ACS telah menetapkan dan memastikan untuk melakukan tindakan korektif serta perbaikan sesuai dengan ketidaksesuaian yang terjadi, Metode tersebut didokumentasikan di dalam prosedur yang mencakup persyaratan untuk: Peninjauan ketidaksesuaian (termasuk keluhan pelanggan), Penetapan penebab ketidaksesuaian, penilaian untuk memastikan bahwa ketidaksesuaian tidak terulang lagi, penetapan dan penerapan tindakan yang diperlukan, pencatatan hasil tindakan yang dilakukan dan peninjauan tindakan korektif yang dilakukan. Hal diatas sesuai dengan (SNI ISO IEC 17025, 2008) bahwa tindakan perbaikan harus dilakukan setingkat dengan besar dan resiko masalah. Sehingga tindakan koreksi dari keluhan pelanggan menjadikan acuan adanya respon dari tindakan koreksi, tindakan koreksi mengulas semua bahan, proses dan bahan pelengkap lainnya untuk dikaji ulang,jika pada tindakan koreksi ini menemukan sesuatu yang janggal perlu adanya perubahan pada alur tersebut.

\subsection{Dokumen 11: Menetapkan prosedur verifikasi}

Tindakan ini menetukan semua sistem berjalan dengan baik dan terencana. Serta aspek dari tim HACCP berfungsi dengan rencana HACCP. Dari jadwal dapat diketahui bahwa verifikasi HACCP dilakukan audit setiap 3 bulan sekali oleh $\mathrm{HQE}$, Untuk menjaga agar semua berjalan dengan tepat maka dilakukan verifikasi yang rutin dilakukan. Menurut (Tjahja dan Kadarsiman, 2008), tentang frekuensi verifikasi harus cukup untuk mengkonfirmasi bahwa sistem HACCP telah bekerja secar efektif. Kegiatan verifikasi mencakup empat hal yaitu: (1) Validasi HACCP (2) Review hasil pemantauan. (3) pengujian produk. (4) auditing.Hal ini sistem Verifikasi dilakukan untuk menilai apakah semua proses berjalan dengan tepat dan benar sesuai standart yang telah ditentukan serta jika terjadi penyimpangan yang tidak sesuai perlu perubahan alur dan proses dari keseluruhan tahapan.

\subsection{Dokumen 12: Penetapan prosedur penyimpanan dan dokumentasi \\ Penyimpanan dokumen sendiri terdiri} dari beberapa file, untuk penyimpananya berada di departemen quality. Hal ini ditujukan untuk menjamin panduan HACCP berjalan pada setiap proses, dokumentasi ini sebagai bukti keamanan pangan dengan prosedur dan proses yang terdapat pada manual serta menjamin bahwa semua proses dan kegiatan memenuhi peraturan yang telah ditetapkan. Serta membantu dalam mengidentifikasi lot ingredient, bahan pengemas dan produk akhir bila masalah keamanan timbul dan memerlukan penarikan dari pasar, dan yang terakhir dokumentasi ini merupakan sumber tinjauan data yang diperlukan jika diadakan audit HACCP sebagai pembaruan sertifikasi.

Dari kesuluruhan sistem dokumen HACCP yang disusun dari prinsip-prinsip dan penerapan HACCP difungsikan dapat mampu membantu mengembangkan pelatihan tertentu yang akan mendukung rencana HACCP. Dokumen ini memandu intruksi kerja dari karyawan dan menjadi acuan dalam prosedur tugas yang akan dilaksanakan pada setiap kendali kritis serta menekan dan menghilangkan adanya potensi bahaya (kimia, fisik, mikrobiologis) pada raw material, proses dan produk ready to eat, sehingga menghasilkan produk makanan yang aman, hal ini akan mempengaruhi kepada tingkat kepuasan konsumen dan mempertahankan sertifikasi HACCP yang diperoleh.

\section{KESIMPULAN}

Perusahaan telah membuat perencanaan HACCP sebagai panduan untuk semua proses yang akan berlangsung didalam perusahaan, bertujuan untuk mengetahui titik kritis, tahapan, bahaya yang ditimbulkan, critical limit, monitoring prosedur dan record dari semua kegiatan, corrective, record, dan 
verifikasi. Semua disusun berdasarkan prinsipprinsip HACCP untuk keseluruhan proses. Penerapan critical control point terdapat di 5 tempat yaitu receiving, storage, cooking, blast chilling dan portioning. Di setiap titik kritis ini, suhu kritis standart adalah berbeda beda. Bahan yang tidak memenuhi standard ditolak untuk diproses selanjutnya. Dalam hal bahaya mikrobiologi dilakukan pengecekkan melalui uji sampel pada bahan makanan, makanan ready to eat, dry good, uji udara, hand swab, peralatan produksi, air dan ice cube. Pelaksanaan masing-masing pengujian sampel sudah ditetapkan oleh PT. Aerofood ACS Surabaya berdasarkan prosedur standard. Jika hasil pengecekkan tidak memenuhi standart maka dilakukan perbaikan penanganan atau pengubahan alur prosedur handling.

\section{DAFTAR PUSTAKA}

AEA. 2006. Hygiene Guidelines. The Association of European Airlines, Brussels, Belgum, 2006, pp,1-24.

Araújo, W. M., Zandonadi, R. P., Tenser, C. M., Farage, P., and Ginani, V. C. 2018. Importance and Level of Adoption of Food Safety Tools in Food Services. Journal of Culinary Science \& Technology, 1-20.

Ayman Safi Abdelhakima, Eleri Jonesb, Elizabeth Redmondc, Mahmoud Hewedia, Phillip Seamand. 2019. Cabin Crew Food Safety Training: a Qualitative Study. Food Control, 96: 151-157.

Badan Standardisasi Nasional (BSN). 1998. Standar Nasional Indonesia- SNI 014852-1998: Sistem Analisis Bahaya dan Pengendalian Titik Kritis (Hazard Analysis Critical Control Points-HACCP) serta Penerapannya. BSN. Jakarta.

Balan S., H.A. Razzak \& S. Manikandan. 2018. Creating a Competitive Advantage in the Global Flight Catering Supply Chain: a Case Study Using SCOR Model. International Journal of Logistics Research and Applications 21(5): 481-501.

El-deen, R. M. B., S. B. Hasan, and N. M. Fawzy. 2016. The Effect of Airport and In-flight Service Quality on Customer
Satisfaction. Journal of Faculty of Tourism and Hotels 10 (1/2): 34-45.

Emirates Flight Catering. 2017. Food Production. Accessed December 28, https://www.ekfc.com/services/foodpr oduction/.

Farah Diana Ishak, Fairuz I. Romli, Kawthar Abdul Rahman. 2018. Public Survey on New In-Flight Food Delivery and Waste Collection System. Journal of Mechanical Engineering SI 5(4): 142152.

Ko Y. 2016. An Airline's Management Strategies in a Competitive Air Transport Market. Journal of Air Transport Management 50: 53-61.

Latorres, J. M., Rancatti, A., Lasta, D., Queiroz, M. I., and Mitterer-Daltoé, M. L. 2016. Cognitive Evaluation as a Food Safety Tool a Food Handler Case Study. Journal of Food Safety 36(4): 497-502.

Lee, J., and S. Ko. 2016. Effect of the In-flight Meal Service Quality on the Customer Value and Loyalty. Indian Journal of Science and Technology 9 (26): 1423.

Lin, W. 2017. Catering for Flight: Rethinking Aeromobility as Logistics. Environment and Planning D: Society and Space. doi:10.1177/0263775817697977.

Meta, S., Možina, S. S., Levstek, S., Kukec, A., Raspor, P., \& Jevšnik, M. 2018. Food Safety Knowledge, Self-Reported Practices and Attitude of Poultry Meat Handling Among Slovenian Consumers. British Food Journal 120(6): 1344-1357.

Moreb, N. A., Priyadarshini, A., \& Jaiswal, A. K. 2017. Knowledge Of Food Safety and Food Handling Practices amongst Food Handlers In The Republic Of Ireland. Food Control 80: 341-349.

Mosteller, T.M and Bishop, J.R. 2003. Sanitizer Efficacy Against Attached Bacteria in a Milk Biofilm. Journal of Food Protection 56: $34-41$

Muhandri, T. dan D. Kadarisman. 2005. Sistem Jaminan Mutu Pangan. Fakultas Teknologi Pertanian. Institut Petanian Bogor. Bogor 
Versi Online:

http://www.profood.unram.ac.id/index.php/profood e-ISSN: 2443-3446

Murray, R., Glass-Kaastra, S., Gardhouse, C., Marshall, B., Ciampa, N., Franklin, K., et al. 2017. Canadian Consumer Food Safety Practices and Knowledge: Foodbook Study. Journal of Food Protection 80(10): 1711-1718.

Romli, F. I., K. Abdul Rahman and F. D. Ishak, 2016. In-Flight Food Delivery and Waste Collection Service: The Passengers' Perspective and Potential Improvement. IOP Conf. Series: Materials Science and Engineering 152

Sel, Ç., M. Soysal, and M. Çimen. 2017. A Green Model for The Catering Industry under Demand Uncertainty. Journal of Cleaner Production 167: 459-472.

Sternberg, H., and H. Harispuru. 2017. Identifying Root Causes of
Pro Food (Jurnal Ilmu dan Teknologi Pangan)

Vol 5 No. 1 Mei 2019 ISSN: 2443-1095

Inefficiencies in Road Haulage: Case Studies from Sweden, Switzerland and Germany. International Journal of Logistics Research and Applications 20 (1): 73-83.

Thaheer, Hermawan. 2005. Sistem Mnajemen HACCP (Hazard Analysis Critical Control Points). PT Bumi Aksara. Jakarta.

Zanin, L. M., da Cunha, D. T., de Rosso, V. V., Capriles, V. D., and Stedefeldt, E. 2017. Knowledge, Attitudes and Practices of Food Handlers in Food Safety: An Integrative Review. Food Research International 100: 53-62. 